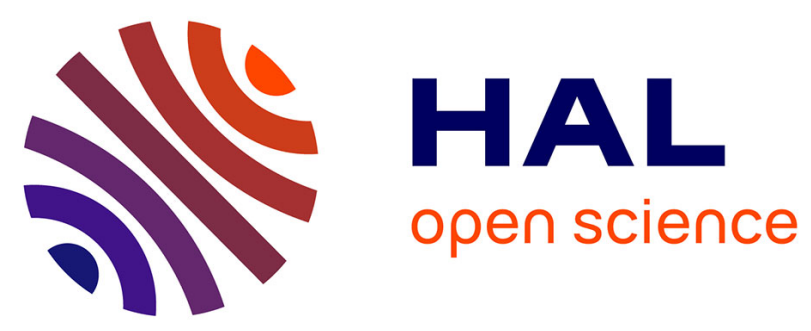

\title{
Investigating Factors that Influence the Adoption of BI Systems by End Users in the Mining Industry in Southern Africa
}

\author{
Sunet Eybers, Marie J. Hattingh, Liako Kuoe
}

\section{To cite this version:}

Sunet Eybers, Marie J. Hattingh, Liako Kuoe. Investigating Factors that Influence the Adoption of BI Systems by End Users in the Mining Industry in Southern Africa. 18th Conference on e-Business, e-Services and e-Society (I3E), Sep 2019, Trondheim, Norway. pp.113-124, 10.1007/978-3-030-293741_10. hal-02510122

\author{
HAL Id: hal-02510122 \\ https://hal.inria.fr/hal-02510122
}

Submitted on 17 Mar 2020

HAL is a multi-disciplinary open access archive for the deposit and dissemination of scientific research documents, whether they are published or not. The documents may come from teaching and research institutions in France or abroad, or from public or private research centers.
L'archive ouverte pluridisciplinaire HAL, est destinée au dépôt et à la diffusion de documents scientifiques de niveau recherche, publiés ou non, émanant des établissements d'enseignement et de recherche français ou étrangers, des laboratoires publics ou privés. 


\title{
Investigating factors that influence the adoption of BI systems by end users in the mining industry in Southern Africa.
}

\author{
S. Eybers ${ }^{1[0000-0002-0545-3688]}$, M.J. Hattingh ${ }^{2[0000-0003-1121-8892]}$, L. Kuoe ${ }^{3[0000-0001-9310-4519]}$ \\ ${ }^{1}$ University of Pretoria, Private Bag X20, Hatfield, 0028, sunet. eybers@up. ac. za \\ ${ }^{2}$ University of Pretoria, Private Bag X20, Hatfield, 0028, marie. hattingh@up. ac. za \\ 3. University of Pretoria, Private Bag X20, Hatfield, 0028, liakokuoe@ gmail .com
}

\begin{abstract}
In an information society, information has become one of the most valuable asserts to an organisation. This is even more important in the mining industry in Africa where production lines are highly sensitive and decision makers are dependable on correct information to make decisions. One of the systems that can provide for the information needs of an organisations - Business Intelligence (BI) systems - unfortunately has a high failure rate. Some of the reasons can be attributed, to technical issues (such as data structures, data warehouses), process issues (information retrieval processes and analysis), human issues (resistance to adoption) and the complex nature of BI.

This qualitative study investigated the adoption of BI systems by end users by considering the work environment and user empowerment as suggested by Kim and Gupta [1]. Data was gathered using semi-structured interviews considering both aspects of the work environment and user empowerment.

The findings of the study suggested that a strong bureaucratic culture and strict safety regulatory requirements inhibits job autonomy. Job autonomy in return has a negative impact on the willingness of end users to create their own BI reports. Poor management support and a lack of training in the utilisation of BI systems furthermore make it difficult for the ageing workforce to use all the advanced features of the BI systems and capabilities. Finally, end users felt a lack of empowerment to make business decisions and therefor lack motivation to use the system.
\end{abstract}

Keywords: BI systems, mining, user empowerment, work environment

\section{Introduction}

One of the many goals of a business is to seek profit through offering a market-leading product or service that yields profitable returns for shareholders, which in turn provides continuity and growth to a company [2]. Management is responsible for directing and making strategic decisions that will see an organisation operate in the most efficient and effective manner. On a daily basis, managers face a variety of challenges such as: 
leadership adjustment, talent management, technology, organisational culture and decision making [3]. Despite these daily challenges, managers need to constantly explore ways of improving the organisation's performance. Business Intelligence (BI) systems aims to assist management on challenges such as decision making, by providing timeous, accurate and reliable means of making informed decisions and predictions about the future [4]. The right strategic decisions can differentiate a product or service from its rivals, thus, increasing market share and competitiveness.

BI refers to the combination of operational data (which is usually raw data), processes, systems and applications to give business leaders competitive information that is crucial for decision making [5,6]. BI helps executives to be more proactive by analysing the past to improve the future. It is predicted that by the year 2021, the growth of modern BI will double when compared to its mainstream counterparts, and that it will deliver greater business value [7]. However, organisations fail to achieve a return on their BI system implementation investments [1, 8, 9]; [10].

Although organisations invest in BI for its recognised benefits, the actual realisation of BI benefits lies in the effective use of BI systems [11]. Service oriented BI has brought about new social and cognitive challenges such as the abandonment or subutilisation of the BI System [10]. Other challenges such as complex system implementation (due to multiple data source systems and multiple data owners for example), lack of alignment with business strategy and the absence of a clear project objective all contribute to the complexity of BI projects $[10,12,13]$. One way of addressing these challenges are to focus on BI system utilisation [10].

An end user's adoption and subsequent satisfaction to utilise a system has a direct impact on the benefits obtained from the system implemented [4]. This study focus on the factors that influence the adoption of BI systems by end users in the mining industry in South Africa (SA). Research on the successful adoption of BI systems in a SA context is emerging (see section 2) and this paper aims to contribute to that body of literature.

The research question is "How does end users influence the adoption of BI systems", particularly focusing on the impact of the user workplace environment, the attitude of end users towards the BI system and the willingness of users to utilise the BI system.

The paper outline is as follow: the first section considers current BI system utilisation success factors in SA context, the relationship between BI system adoption and end user satisfaction and subsequently BI system usage as a measure of BI system adoption. The research approach followed is presented in section 4 followed by the discussion of the findings in section 5. Sections 6 and 7 presents the conclusion and recommendations.

\section{BI system utilisation and success in a South African context}

How BI systems are used in an orginisation is dependent on the objectives each orginisation aims to achieve [14]. BI systems are mainly used to analyse organisational data that is generated from operational activities for the customer relations purposes, process monitoring [15] and strategic purposes, to determine threats through the analyses of internal and external environments [16]. 
Dawson and Belle [17] conducted a study to understand the critical success factors (CSFs) most important to financial services in SA. Their study revealed that the most important CSFs were committed management support, business vision, user involvement and data quality. Eybers \& Giannakopoulos [18] also looked at the CSFs South African organisations can use to improve their chances of BI project success by looking at different organisations. The results indicated that CSFs in BI implementations are somewhat generic. Organisational factors, project related factors, technical factors and environmental factors were the categories found in both academic literature and in responses from the interviewees [18]. An additional category was identified as "external factors", possibly indicating that some CSFs are industry specific [18]. Nkuna's [19] research was focused on the utilisation of a BI system as a key factor of BI system success. The findings suggested that perceived usefulness of a BI system will positively affect the intention to use a system, whilst perceived ease of use has a positive effect on perceived usefulness but has no influence on intention to use the BI system. Serumaga-zake [4] reported that that user satisfaction played a mediating role between system and service quality with net benefits whilst information quality had no significant influence on perceived net benefits.

\section{BI system adoption and user satisfaction}

User satisfaction, as a result of end user system adoption contribute to the success of BI systems. User satisfaction, which is defined as: "an affective attitude towards a specific computer application by someone who interacts with the application directly" [11]. This measure is a subjective measure based on the BI user's perception of the BI system used, which can be influenced by a vast number of variables [5]. End user computing satisfaction (EUCS) is a five-factor measuring instrument developed by Doll \& Torkzadeh (1988) cited in [11]. Its purpose is to measure satisfaction within the end user computing environment; however, [11] believes that the instrument can also be used to evaluate BI systems. The five factors of EUCS are; Content, accuracy, format, ease of use and timelines (Doll \& Torkzadeh, 1988) cited in [11]. These factors are important for management and stakeholders of BI systems as it contributes to a positive computing satisfaction.

Panahi [20] posited that user satisfaction is a factor of technological BI capabilities (i.e. data quality, functionality, access and flexibility), as well as organisational BI capabilities (i.e. comprehensive training, quality of support and the type of use). In Panahi's [20] research it was shown that the higher the technological factors are, the higher the user satisfaction was likely to be. This means that, for a BI implementation to be successful, the data, accessibility, functionality and flexibility need to be of highest quality. In addition to this finding, organisational BI capabilities also proved to be very significant in determining user satisfaction, thus BI success. Similarly, Serumagazake [4] findings also report system quality (i.e. availability, ease of use, accessibility, stability) and service quality (i.e. assurance, responsiveness and knowledge) as important factors to user satisfaction and BI success. 
Isik et al. [5] refer to five BI satisfaction measures based on the BI system used, to evaluate BI success. These five measures are; user friendliness, timeous and precise decision making support and lastly the overall satisfaction of BI system users. The usage of the BI system, due its importance, is further explored in the next section.

\subsection{BI usage as a measure of BI system success}

Between $10 \%$ and $20 \%$ of BI projects are abandoned or the implemented system is not utilized as intended. [10]. This highlights the importance to measure BI usage in order to determine BI success.

BI systems hold quality information that assists decision makers with insightful information that they can use for decision making. The measurement of the type of BI use (i.e. frequency or intensity of use) is therefore an important measure as it measures the realisation of meaningful use, which has a direct impact on productivity and success [21]. BI usage therefore has a direct impact on the ability to make decisions [21].

Jones and Straub [22] measured BI usage by considering six areas, namely; frequency of use, duration of use, extent of use, decision to use (use or not use), voluntariness of use (voluntary or mandatory), features used, and task supported. Similarly, Lee et.al (2003, cited in [11]) proposed four measures of system usage as; frequency of use, amount of time spent using the BI system, the actual number of times the system was used and diversity of usage. The study postulated that, if the system is used for a longer period of time, by a large number of users for various reasons of meaningful usage, the $\mathrm{BI}$ system is considered to be successful.

A number of frameworks/models have been published in academic literature investigating the influence of system end users on the adoption of BI systems. These include the BI system success model (Hackney et al. 2012), BI system success model [4], CSF framework for implementation of a BI system [12], Business Intelligence Extended Use (BIEU) model [21] and User Empowerment approach to IS Infusion [1].

The User Empowerment approach to Information System (IS) Infusion by Kim and Gupta [1] was selected as the theoretical underpinning for the study based on the strong focus on the system user. Although it focuses on IS, BI is perceived as a subset of IS and in many cases BI faces the same challenges as IS [8]. The model, as illustrated in Figure 1, does not focus on technological factors or the external macro environmental characteristics but rather social aspects of IS system adoption. Due to space limitations, this paper will only report on the work environment and the user empowerment aspects.

The work environment aspect refers to the importance of the work environment in the psychological empowerment of end users toward the adoption of IS systems. This view is similar to the social cognitive theory as described by [4] which states that there is an interaction between human behavior and the environment. The approach suggests that the design of the work environment has an influence on a Business intelligence user's psychological empowerment. This framework focuses primarily on Information system (IS) users and not the general employees [1]. Perceived fit, job autonomy and climate for achievement are the main factors that influences an end users' view on work environment [1]. 


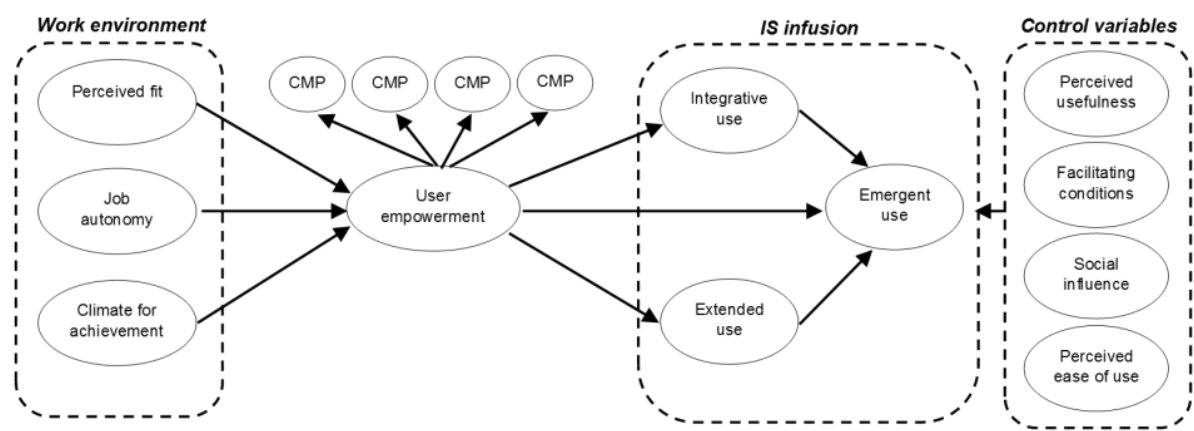

Fig. 1. A user empowerment approach to information systems infusion [1]

User empowerment is based on the theory of psychological empowerment as postulated by [23]. The user empowerment section contains four 'cognitions' or end user perceptions that influence an individual's character namely competence (CMP), impact (IMP), meaningfulness (MNG) and finally choice or self-determination (SDT) [1]. Each of these factors will be discussed further in section five.

\section{$4 \quad$ Research approach and data collection}

The primary objective of this research is to investigate the influence of end user system adoption of BI systems in a mining firm in South Africa. Based on the objective, the study explores the "subjective views" of different BI users and are therefore qualitative in nature. This approach will allow the researcher to explore and to gain new insights as to how end user adoption influence BI implementations in an organisation.

Company X has two operating mining plants in the Northern Cape Province, South Africa. The mining operations are approximately 150 kilometers apart. These mines are both open pit iron-ore mines.

The research focused on respondents from the Business Improvement department, Human Resources (HR) departments located at the two mines as well as the Head Office. Within each department, different levels of employees were targeted, including senior managerial level employees, HR and Business Improvement practitioners, general end users, business analysts. This diverse sample population represented the views of employees in their respective departments and locations. These two departments were an area of interest because in the past, they had implemented a number of BI projects in an effort to analyse and improve the productivity in the mine. A total of 30 participants were asked to participate in the research whilst 20 participants gave their consent.

Semi-structured interviews were conducted using the user empowerment approach to IS infusion [1] to cover various aspects of end user system adoption. The interview template consisted of three sections. The first section focused on soliciting demographic information of the interviewees. The second section aimed at understanding the work environment of the BI users. The third section of the interview focused on personal behaviors and attributes that influence BI system use. 
After the construction of the interview template, a pre-test was conducted to test the appropriateness of questions and perform quality control. Two colleagues from the researcher's IT department completed the interview template during this process where after minor amendments were made.

The interview template was emailed to employees who were unable to attend faceto-face interviews. Due to geographic constraints, telephonic interviews were also conducted.

\section{$5 \quad$ Discussion of findings}

The discussion section follows the outline of the user empowerment approach to information systems infusion [1] and include the work environment and user environment.

\section{$5.1 \quad$ Work environment}

The work environment is influenced by the perceived fit of the technology to the task, the degree of job autonomy and the climate of achievement [1]. Each of these factors will be discussed in turn.

Perceived fit of the BI system. The perceived fit between an application and the needs of the end user include the extent to which the system caters for basic end user needs as well as the provision of knowledge that can be actioned by a novice or expert user [1]. According to the findings, $50 \%$ of the respondents believe the BI system, in particular the systems are not integrated into their daily job tasks. $35 \%$ of users have a neutral feeling towards the BI system. 15\% of the employees believe the BI systems fit fairly well into their daily tasks. Despite the neutral feeling towards the system, end users are optimistic towards the capabilities of the system. They believe the BI system compliments some of their work tasks. This was similar to findings in a study conducted by Nkuna [19] that there is a relationship between the perceived ease of use of systems and their perception of the system being suitable or appropriate for completing tasks. The job the users do have a great influence on whether employees find the system fitting or not. Employees working in the Business Improvement department stated that they felt the system fitted well in their work environment. This is mainly due to the nature of their work which include the ongoing task of finding ways to improve the business. Respondent 5 explained: "We use the control charts in our daily caucuses to discuss previous performances and plans for the day".

HR employees on the other hand have a range of feelings on the system's fit to work. Most of the respondents felt that their BI system did not fit their job. The essence of this view is captured through respondent 16's response: "I have to use my free time during lunch or after work if I want to use the tool". In support of the above view, Respondent 12 stated that: "I don't often use it. The reports on the tool do not support my work"

In summary, the findings are: 
- Using BI systems to support decision making is a fairly new process at the Mine. The importance of user oriented change management in new BI systems is acknowledged as a critical success factor of BI implementations by Eybers \& Hattingh [24].

- $50 \%$ of the employees believe the BI systems does not fit well into their daily tasks, $35 \%$ of the employees perceive that the BI systems fits well into their daily tasks and $15 \%$ of the employees believe the BI systems fit fairly well into their daily tasks.

Job autonomy. Kim \& Gupta [1] hypothesize that job autonomy is another work environment factor that has a significant effect on user empowerment. The outcomes of the job are dependent on an individual's drive or initiatives rather than on instructions [1]. Job autonomy creates a care around a job which then enhances an individual's motivational disposition to use a system [1]. Based on this, the interviewees were then questioned about the BI system and whether or not they felt the system gave them the independence and freedom to conduct work on their own conditions.

Most of the respondents' views suggest that the nature of the Mine is not a conducive environment for job autonomy. Furthermore, respondents cited that their work was set around production targets and standard working procedures which makes job autonomy difficult. This view is captured Respondent 10: "Most of the work we do is guided by standard work procedures. There are steps we have to follow to conduct work and we can't deviate from as that can put us at a health risk".

Emphasis on the lack of job autonomy, Respondent 9 stated: "Guided by daily production targets therefore it is difficult to set own targets".

In summary, the findings are:

- In both the HR and the Business Improvement departments, employees felt that the mine's organizational structure does not allow for job freedom due to predefined set targets.

- Supervisors monitor employee performance and ensure targets are met which inhibits BI system users to make their own decisions.

- Legislation are strictly enforced by the Department of Mineral Resources through the Safety Act in SA. The act specify certain how certain tasks should be completed and therefore makes it difficult for job independence or freedom to perform work.

- Predefined BI reports prohibit the user to define their own reports.

Climate for achievement. Climate for achievement is a social structure that provides a frame of reference for individuals' perceptions about the work environment [1]. It is the foundation of attitudes and beliefs and it informs the user on what is important and what is not. Interviewees were questioned about the BI system and whether or not they felt the system provided them with a platform to achieve more. The objective was to also understand if the mine had established ways of encouraging a culture of excellence and of achievement. Respondent 3 stated: "The organisation does not really recognise us for using the tool". This was supported by Respondent 1 who indicated that they are unsure of the BI system capabilities: "We do not know the capabilities of the BI system. We are not sure what it can do". 
Employees have a need to achieve more but the organisation is not empowering them with the correct skillsets to achieve more. This is encapsulated in the following response by Respondent 6: "I think I can do more with the system, but I am not sure".

The following provide a summary of the findings:

- The BI users generally have a high appetite for achievement.

- Majority of BI users have basic BI skills, this makes it difficult to explore more of the system's functionality.

- There is a need to create an environment where employees feel empowered.

- Lack of senior management's support in using the system negatively affects the utilisation of the BI systems and technologies. Management support is crucial towards achieving a successful BI implementation [24, 25].

\subsection{User empowerment}

User empowerment is a social construct that examines an individual's motivational orientation in relation to their work [1]. Motivation enables individuals to conduct work more effectively to improve work performances [1]. It is important for this research to examine the antecedents of user empowerment (competence, impact, meaningfulness and self-determination) and their influence on BI use. Each of these will be discussed in turn.

Competency of the user. Competence relates to self-efficacy. It is the degree of selfbelief an individual has towards their own capabilities to effectively conduct tasks [23]. Most of the respondents believed that they were competent in conducting their jobs. They believe they have the adequate capabilities to effectively deliver work. Regarding their competency with the BI system, the respondents believed that their poor skill levels hindered their competency. They believe that their competency improved when they took an initiative to learn more (i.e. climate to achieve). Respondent 18 stated: "I had no formal training. I am self-taught. The more I use the system the more I learn more about it."

It was observed that users who have a climate to achieve are more competent than those with a lower climate to achieve. Training plays a pivotal role in improving employee competency. Trained users felt comfortable with the system and more competent. In support of this, Respondent 2 stated: "We just started receiving training on using the system and now I am a bit confident".

As a result of the feedback received from respondents the following findings could be synthesized, similar to critical success factors identified by Eybers \& Hattingh [24]:

- Employees believe that they are competent in conducting their work.

- Employees believe that their competency level will be reduced if they use the BI system.

- Employees believe that BI system training will improve their competency levels.

- Employees have limited basic skills to create their own reports. 
Impact of system usage. This antecedent to user empowerment reflects an individual's level of influence on work outcomes based on system use [1, 23]. In order to understand the BI system users' views on the impact of the system, the interviewees were questioned about their views on the impact they have on the organisation/respective departments, including the impact of using the BI system.

The results showed that users with great levels of influence are senior managers or supervisors. This is expected as they hold managerial roles. Management uses BI reports to make quick operational decisions. The high level of influence is attributed to that fact that they, as managers, are accountable for achieving production targets. Respondents from both HR and Business Improvement departments shared the same views that, the results produced by BI systems influences their actions. A Business Improvement respondent stated that: "For short interval controls, the system results influence strategic actions". (Respondent 5)

Similarly, an HR respondent stated: "For HR reports such as absenteeism, the results influence strategic actions”. (Respondent 16)

In contrast, non-managerial employees believed they have a low influence on how work objectives can be achieved. Respondent 20 suggested: "We can give suggestions to the supervisor", whilst Respondent 14 felt: "Do not have the power to influence operation". The following findings could be synthesized:

- Senior managers or supervisors have a great level of influence.

- Lower level employees believe they have less influence on how work objectives can be achieved.

Meaningfulness of the system. Meaningfulness refers to the value a task has to an individual's personal development plans i.e. the level at which the tasks completed by an employee contribute towards their individual own goals, standards and beliefs [23]. The level of meaningfulness will affect the employee's determination thus influencing their motivation [26]. It relates to the harmonious relationship between the BI user's values/standards and the BI system's values [1]. In order to understand the BI users' orientation regarding meaning, the interviewees were questioned about the meaningfulness of regarding the BI system.

Some of the respondents felt that the system added some form of value. They believe in the system's objectives and aims. Although some respondents use the system only when needed, they still believe in the capabilities and values of the BI system. The respondents felt the system's objectives were aligned to their own values and standards. Those who just started using the system or those who knew little of the system still believed the system is an enabler and will influence them positively especially when the system is aligned to business requirements. This is evident in Respondent 2' statement: "We just started using the system but believe it will assist us."

A system that does not meet business requirements does not add value to its end users. It is therefore important that the views and requirements of end users are adhered to. The realisation of user requirements through the system's functionality creates value to its users. Respondent 5 supported this by stating: "Our department defined the requirements, so it does bring a lot of value". One user indicated a reluctance to change 
from old legacy solutions to using new BI systems. Users who have spent years building a solution using MS Excel are committed to and trust their own "systems".

The following findings could be synthesized:

- The business intelligence system can contribute to achieving business value. In areas where legacy systems are used, the value of the new BI system is compromised.

- Business value is achieved if reporting requirements are met and the system integrated into their daily work.

Self-determination. Self-determination relates to an individual's sense of choice [1, 26]. A lack of power to make choices gives employees a sense of autocratic leadership which they tend to be negative towards, this then leads to tensions and a decrease in self-esteem [26].The interviewees were questioned about the choices they have when using the BI system. As seen with the results from analysing job autonomy in the previous section, users of the BI system believe they do not have much choice when it comes to deciding on their work tasks and schedules.

It is due to aspects such as committing to production targets, adhering to standard work procedures, mine safety controls, planned routine work and vertical organisational structures that make it difficult for employees to plan their own work schedules and deliverables. According to the respondents, self-determination is negatively influenced by routine work, standard operating procedures, organisational structures and target oriented tasks. Respondent 9 stated: "I am guided by daily production targets therefore it is difficult to set my own targets" confirmed by Respondent 10 who stated: "Most of the work we do is guided by standard work procedures. There are steps we have to follow to conduct work". In summary, it can be concluded that BI users generally not empowered to take and be held responsible for business actions.

\section{Conclusion}

The study's findings identified numerous factors affecting the adoption of the BI system at a mining organisation. Factors related to the work environment suggests that the availability of a BI system that supports decision making is a fairly new concept at the mine. The user's perception of the BI system's ability to support their daily tasks were inconclusive. However, the majority of participants believed that the availability of data in the BI system could support them in performing daily tasks. The strong bureaucratic culture and nature of the mining work environment inhibits job autonomy. The environment is characterized by prescheduled tasks based on achieving clear set targets carefully managed by supervisors. The industry is furthermore regulated by prescriptive legislation which requires the creation of pre-defined reports for BI users leaving little room for the development of customized reports. The culture of the mining environment influences the climate for achievement. Although BI users have a high appetite for achievement their basic BI system skills inhibit them from achieving more using the BI systems. This is furthermore negatively influenced by the lack of senior management to acknowledge the benefits of using the BI systems. 
The BI users in general were not empowered to utilise the BI system to its full potential. Factors pertaining to user empowerment suggested that BI users were generally not trained, and therefore didn't use, the advanced capabilities of BI systems and technologies. Even if they do get BI system training, study participants felt that they are not empowered to make business decisions.

\section{$7 \quad$ Recommendations}

The following recommendations are made: to improve BI implementations at the mine:

- Upskill workforce. The organization currently employ a relative older generation (above 40 years of age). These workers need to be trained in using specialized systems and technologies as part of BI systems.

- Create awareness. The mine needs to invest time and financial resources to create awareness of the availability, objectives and capabilities of BI systems.

- Management support. Mine managers, union leaders and supervisors should support the utilisation of BI systems and should set an example for using the BI systems.

- Suitable system for the task: Implement BI solutions in areas that can have a positive, visible impact on organisational performance.

\section{References}

1.Kim, H., Gupta, S.: A User Empowerment Approach to Information Systems Infusion. IEEE Trans. Eng. Manag. 61, 656-668 (2014).

2.Bagnoli, C., Biloslavo, R., Rusjan Figelj, R.: Managing dualities for efficiency and effectiveness of organisations. Ind. Manag. Data Syst. 113, 423-442 (2013). https://doi.org/10.1108/02635571311312695.

3. McAfee, A., Brynjolfsson, E.: Big Data: The Management Revolution. Harv. Bus. Rev. 6069 (2012).

4. Serumaga-zake, P.: The role of user satisfaction in implementing a Business Intelligence System. South Afr. J. Inf. Manag. 19, 1-8 (2017).

5.Isik, O., Jones, M., Sidorova, A.:Business Intelligence (BI) Success And The Role Of BI Capabilities. Intell. Syst. Account. Finance Manag. 18, 161-176 (2012). https://doi.org/10.1002/isaf.

6. Thamir, A., Poulis, E.: Business Intelligence Capabilities and Implementation Strategies. Int. J. Glob. Bus. 8, 34-45 (2015).

7. Sallam, R., Howson, C., Idoine, C., Oestreich, T., Laurence, J.: Magic Quadrant for Business Intelligence and Analytics Platforms, https://www.gartner.com/home) Gartner.

8. Clavier, P., Lotriet, H., Van Loggerenberg, J.: A First Step Towards Service-Dominant Logic As A New Approach To Overcome Challenges In Business Intelligence.1, 220231 (2014). https://doi.org/10.5121/ijmpict.2012.3201.

9. Katsikogiannis, G., Kallergis, D., Garofalaki, Z., Mitropoulos, S., Douligeris, C.: A policyaware Service Oriented Architecture for secure machine-to-machine communications. Ad Hoc Netw. 80, 70-80 (2018). https://doi.org/10.1016/j.adhoc.2018.06.003.

10. Díaz Pinzón, B.H., Villamarín García, J.M.: Key success factors to business intelligence solution implementation. J. Intell. Stud. Bus. 7, 48-69 (2017). 
11. Hou, C.: Examining the effect of user satisfaction on system usage and individual performance with business intelligence systems : An empirical study of Taiwan 's electronics industry. Int. J. Inf. Manag. 32, 560-573 (2012). https://doi.org/10.1016/j.ijinfomgt.2012.03.001.

12. Yeoh, W., Koronios, A.: Critical Success Factors for Business Intelligence Systems. J. Comput. Inf. Syst. Spring ABIINFORM Glob. Pg. 50, 23-32 (2010). https://doi.org/10.1080/08874417.2010.11645404.

13. Lautenbach, P., Johnston, K., Adeniran-Ogundipe, T.: Factors influencing business intelligence and analytics usage extent in South African organisations. South Afr. J. Bus. Manag. 48, 23-33 (2017). https://doi.org/10.4102/sajbm.v48i3.33.

14. Vandenbosch, B., Huff, S.: Searching and scanning: How executives obtain information from executive information systems. MIS Q. 21, (1997).

15. Elbashir, M.Z., Collier, P.A., Davern, M.J.: Measuring the effects of business intelligence systems: The relationship between business process and organizational performance. Int. J. Account. Inf. Syst. 9, 135-153 (2008). https://doi.org/10.1016/j.accinf.2008.03.001.

16. Lönnqvist, A., Pirttimäki, V.: The Measurement of Business Intelligence. Inf. Syst. Manag. 23 ,

$32-40$

(2006). https://doi.org/10.1201/1078.10580530/45769.23.1.20061201/91770.4.

17. Dawson, L., Van Belle, J.-P.: Critical success factors for business intelligence in the South African financial services sector. SA J. Inf. Manag. 15, 1-12 (2013). https://doi.org/10.4102/sajim.v15i1.545.

18. Eybers, S., Giannakopoulos, A.: Identifying Critical Success Factors for Business Intelligence Systems. J. Comput. Inf. Syst. (2015). https://doi.org/10.1080/08874417.2010.11645404.

19. Nkuna, D.: Business Intelligence usage determinants: an assessment of factors influencing individual intentions to use a Business Intelligence system within a financial firm in South Africa, (2011).

20. Panahi, P.: Business intelligence capabilities and user satisfaction. https://gup.ub.gu.se/file/143471 last accessed 2019/03/01.

21. Grubljesic, T., Jaklic, J.: Conceptualization of the business intelligence extended use model. J. Comput. Inf. Syst. 55, 72-82 (2015). https://doi.org/10.1080/08874417.2015.11645774.

22. Jones, A.B., Straub Jr., D.W.: Reconceptualizing System Usage: An Approach and Empirical Test, Information Systems Research. Inf. Syst. Res. 17, 228-246 (2006). https://doi.org/10.1287/isre.1060.0096.

23. Spreitzer, G.M.: Psychological Empowerment in the Workplace: Dimensions, Measurement, and Validation. Acad. Manag. Nurnnl. 18, 42-1465 (1995). https://doi.org/10.2307/256865.

24. Eybers, S., Hattingh, M.J.: Critical success factor categories for big data: A preliminary analysis of the current academic landscape. In: 2017 IST-Africa Week Conference (ISTAfrica). pp. 1-11 (2017). https://doi.org/10.23919/ISTAFRICA.2017.8102327.

25. Mikalef, P., Pappas, I.O., Krogstie, J., Giannakos, M.: Big data analytics capabilities: a systematic literature review and research agenda. Inf. Syst. E-Bus. Manag. 16, 547-578 (2018). https://doi.org/10.1007/s10257-017-0362-y.

26. Thomas, K., Velthouse, B.: Cognitive Elements of Empowerment: An "Interpretive" Model of Intrinsic Task Motivation. Acad. Manage. Rev. 15, 666-681 (1990). 